\title{
Estimación de la sensibilidad y especificidad de dos pruebas diagnósticas para la detección de Mycoplasma suis en Argentina utilizando un modelo bayesiano
}

\author{
Estimation of the sensitibity and specificity of two Mycoplasma suis diagnostic \\ tests in Argentina using a Bayesian model
}

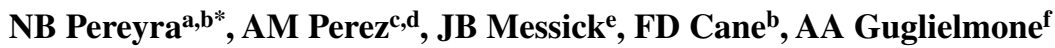 \\ ${ }^{a}$ Cátedra de Microbiología, Facultad de Ciencias Veterinarias, Universidad Nacional de Rosario, Santa Fe, Argentina. \\ b Instituto de Porcinotecnia, Ministerio de la Producción de la Provincia de Santa Fe, Santa Fe, Argentina. \\ ${ }^{\mathrm{c}}$ Center for Animal Disease Modeling and Surveillance, University of California, Davis, USA. \\ ${ }^{d}$ CONICET / Facultad de Ciencias Veterinarias, Universidad Nacional de Rosario, Santa Fe, Argentina. \\ ${ }^{e}$ Department of Pathobiology, Scholl of Veterinary Medicine, Purdue University, West Lafayette, USA.

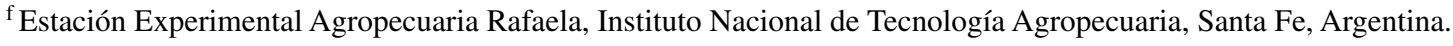

\begin{abstract}
SUMMARY
A prerequisite for understanding the impact of Mycoplasma suis infection on pig production and its epidemiological dynamics in infected regions, is the development of diagnostic techniques to discriminate infected from non-infected populations. The objectives of this study were to confirm the presence of M. suis infection in Argentina, and to estimate the sensitivity and specificity of both an Indirect Immunofluorescent Assay (IIFA) and a Polymerase Chain Reaction (PCR) for the detection of the agent. Blood was collected from 282 pigs belonging to 38 farms. Sensitivity (Se) and specificity (Sp) of the tests were estimated using a Bayesian model for conditional dependant results and without assuming a gold standard. PCR was estimated to be a highly sensitive $(\mathrm{Se}=0.982, \mathrm{CI} 95 \%=0.942-0.997)$ and highly specific $(\mathrm{Sp}=0.946 ; \mathrm{CI} 95 \%=0.873-0.984)$ method for diagnosis of $M$. suis infection in the assessed population. A significantly $(\mathrm{P}<0.05)$ lower sensitivity $(\mathrm{Se}=0.682, \mathrm{CI} 95 \%=0.615-0.753)$ and specificity $(\mathrm{Sp}=0.787, \mathrm{CI} 95 \%=0.712-0.863)$ was estimated for the IIFA. Correlation among tests results was low, both for infected $(\mathrm{R}=0.010, \mathrm{CI} 95 \%=-0.118-0.195)$ and non-infected $(\mathrm{R}=0.049$, CI95\% $=-0.133-0.407)$ individuals. The posterior estimate of the probability of finding an infected animal in the study population, which approximates the prevalence of the disease in the sampled animals, was 0.622 (CI95\% $=0.554-0.684)$. The study was successful in confirming the presence of M. suis infection in Argentina and the accuracy of the PCR for the detection of the agent.
\end{abstract}

Palabras clave: Mycoplasma suis, PCR, prueba de inmunofluorescencia indirecta, cerdos.

Key words: Mycoplasma suis, polimerasa chain reaction, indirect immunofluorescent assay, pigs.

\section{INTRODUCCIÓN}

Mycoplasma suis (antes Eperythrozoon suis) pertenece al grupo de los micoplasmas hemotróficos o hemoplasmas, bacterias altamente especializadas, no cultivables, que parasitan la superficie de los eritrocitos de varias especies de mamíferos. M. suis, como todos los hemoplasmas, fue previamente considerado un miembro del Orden Rickettsiales y de la familia Anaplasmataceae, pero el análisis filogenético basado en las secuencias del gen del ARN ribosomal 16S, así como ciertas características fenotípicas como la falta de pared celular, determinaron su transferencia al género Mycoplasma (Rikihisa y col 1997, Neimark y col 2001 y 2002, Messick 2004).

Los hemoplasmas pueden infectar animales en forma latente sin producir enfermedad, pero si se somete a estos portadores a esplenectomía, estrés u otros factores

\footnotetext{
Aceptado: 03.11.2010.

* Sacco Scarafía 365, (2643) Chañar Ladeado, Santa Fe, Argentina; npereyra@atvet.com.ar
}

inmunosupresores, se provoca la aparición de numerosas bacterias en sangre e inclusive signos clínicos en algunas especies. La detección hematológica de infecciones inaparentes requiere del examen de muestras diarias por largos períodos de tiempo, mientras que las técnicas moleculares facilitan su detección (Messick 2004, Neimark y col 2001). Debido a la imposibilidad de su cultivo in vitro, los hemoplasmas se mantienen por pasajes en animales de laboratorio. Para lograr con éxito la replicación en condiciones experimentales los animales deben esplenectomizarse previamente; en el caso de $M$. suis se utilizan cerdos esplenectomizados, ya que se considera específico de especie (Heinritzi 2000, Neimark y col 2001 y 2002, Messick 2004).

M. suis produce una enfermedad en los porcinos (eperitrozoonosis, hemoplasmosis o anemia infecciosa de los cerdos) cuya forma aguda se caracteriza por un síndrome icteroanémico en animales de engorde. Como consecuencia de una severa anemia hemolítica, los enfermos sufren fiebre, disnea, debilidad e ictericia o palidez en piel y membranas mucosas, y se observan cambios post mórtem característicos como una ictericia generalizada, esplenomegalia y un hígado 
firme de color pardo-amarillento (Splitter 1950, Heinritzi 2000). La enfermedad también incluye otros síndromes como anemia, debilidad y aumento de la incidencia de infecciones respiratorias y digestivas en lechones, anemia asociada a inadecuada conversión del alimento en cerdos de recría y en cerdas, anemias acompañadas de fiebre, baja producción de leche, alteración de la conducta maternal, así como de abortos y natimortos (Henry 1979, Brownback 1981, Zinn y col 1983, Heinritzi 2000). Las tetraciclinas han sido usadas efectivamente para reducir la bacteriemia y aliviar los signos clínicos más severos de la enfermedad, sin embargo, no logran eliminar completamente el microorganismo, por lo que tanto los cerdos tratados como los sobrevivientes que no han recibido tratamiento pueden permanecer como portadores de M. suis (Splitter y Castro 1957, Heinritzi 2000).

En América, la infección por M. suis ha sido reportada en Estados Unidos (Splitter 1950), Canadá (Ayroud y col 1994), Brasil (Guimaraes y col 2007) y Argentina (Kloster y col 1985, Anziani y col 1986). El único estudio serológico realizado a gran escala utilizando la prueba de hemaglutinación indirecta (IHA), reveló que entre el 15 y el $40 \%$ de los cerdos de los Estados Unidos estaban infectados con M. suis (Smith y Tamra 1975), aunque muy probablemente esta prevalencia esté subestimada, ya que luego se determinó que son comunes los resultados falsos negativos con esta técnica (Baljer y col 1989). En Brasil, el estudio de cuatro granjas utilizando la reacción en cadena de la polimerasa (PCR) y el southern blot (SB) encontró que el 33\% de los animales estaban infectados (Guimaraes y col 2006). En Argentina, luego de la primera descripción en 1985, se conocieron reportes que en su mayoría describieron el síndrome icteroanémico en el engorde, por lo que parecería ser la forma más común de la enfermedad (Kloster y col 1985, Anziani y col 1986, Cane y col 1994, Pereyra 2009) pero no se realizaron estudios de prevalencia.

El impacto real de $M$. suis sobre la producción porcina así como algunos aspectos básicos de la enfermedad no están completamente comprendidos. No existe suficiente información sobre las características epidemiológicas y el verdadero comportamiento de la enfermedad en el campo, y esto es el resultado de la falta tanto de técnicas de propagación in vitro de $M$. suis como de una metodología simple y segura para detectar el agente en cerdos portadores (Hoelze 2007). El diagnóstico clásico de una infección aguda se basa en la observación microscópica de formas cocoides o anillares adheridas a los glóbulos rojos en extendidos de sangre teñidos con May GrünwaldGiemsa, pero esta técnica es limitada porque los niveles altos de parasitemia son transitorios y restringidos al inicio de los episodios clínicos, disminuyendo luego substancialmente (Neimark y col 2001, Messick 2004). Mientras tanto, la PCR puede detectar un muy bajo número de microorganismos en muestras clínicas como sangre; se ha estimado que la amplificación del gen del ARNr 16S de $M$. suis usando PCR es un procedimiento altamente específico y sensible y que puede ser usado para detectar la infección en cerdos portadores (Gwaltney y col 1993, Messick y col 1999, Hoelze y col 2003). Para comprender la epidemiología de una enfermedad se necesita realizar estudios sobre un gran número de muestras y el uso de la PCR para detectar la infección por $M$. suis presenta el inconveniente de su costo elevado; por otro lado, conocer la dinámica de anticuerpos es fundamental, pero no se cuenta con tests serológicos confiables para en el caso de $M$. suis. Si bien es esperable que pruebas como la de Inmunofluorescencia Indirecta (IFI) sean menos seguras que la PCR para la detección de la infección, la utilización de la IFI podría representar una estrategia efectiva para reducir el costo del diagnóstico en el campo.

Los objetivos de este estudio fueron confirmar la presencia de la infección por $M$. suis en poblaciones de cerdos de Argentina y estimar la sensibilidad (S) y la especificidad (E) de la PCR y de la IFI para el diagnóstico de la enfermedad. Los resultados presentados aquí son un prerrequisito para el diseño e implementación de estudios a gran escala dirigidos a dilucidar la dinámica epidemiológica y el potencial impacto económico de la infección por M. suis.

\section{MATERIALES Y MÉTODO}

\section{RECOLECCIÓN DE MUESTRAS}

Estrategia de muestreo. Se obtuvieron 282 muestras de sangre de cerdos pertenecientes a 38 granjas localizadas en las zonas de producción porcina más importantes del país: centro y sur de la provincia de Santa Fe, sudeste y sur de la provincia de Córdoba, y norte y centro de la provincia de Buenos Aires. El muestreo incluyó todo el espectro de categorías y sistemas productivos de la región (cuadro 1). Las granjas fueron seleccionadas de acuerdo al interés y voluntad de los propietarios en participar de este estudio. Una de las ventajas de la aproximación bayesiana es que debido a que la estimación a posteriori de los parámetros de interés (en este caso $\mathrm{S}$ y E) se basa en la incertidumbre previa (distribución a priori) y los datos observados a campo, no existe una definición del número de muestras necesarias para ejecutar un estudio como típicamente requiere la estadística frecuentista. En la estadística bayesiana, al aumentar el número de muestras se disminuye la importancia de la distribución a priori y los valores observados adquieren más peso en las estimaciones finales. Contrariamente, un número relativamente bajo de observaciones resultará en una mayor importancia relativa de la incertidumbre capturada en la distribución $a$ priori. Por lo tanto, la pertinencia del número de muestras obtenidas en estadística bayesiana se mide indirectamente mediante la cuantificación de la influencia de las distribuciones a priori en la estimación final de los parámetros en función del número de muestras. La estrategia utilizada 
Cuadro 1. Origen de las muestras recolectadas por provincia, categoría productiva, tipo de manejo y número de granjas.

Origin of colected samples by province, category, type of management, and number of farms.

\begin{tabular}{|c|c|c|c|}
\hline & & Número de muestras & Número de granjas \\
\hline & Número total & 282 & 38 \\
\hline \multirow[t]{3}{*}{ Provincia } & Santa Fe & 154 & 22 \\
\hline & Córdoba & 79 & 11 \\
\hline & Buenos Aires & 49 & 5 \\
\hline \multirow[t]{2}{*}{ Manejo } & Aire libre & 163 & 26 \\
\hline & Confinamiento & 119 & 12 \\
\hline \multirow[t]{5}{*}{ Categoría productiva } & Reproductores & 42 & 5 \\
\hline & Terminación & 179 & 14 \\
\hline & Desarrollo & 13 & 3 \\
\hline & Recría & 30 & 13 \\
\hline & Lechones & 18 & 8 \\
\hline
\end{tabular}

para medir la sensibilidad del análisis a los valores de las distribuciones a priori se discute en el apartado de análisis estadístico.

Tipo de muestras recolectadas. De cada animal muestreado se recolectó sangre en dos tubos, uno conteniendo ácido etilendiamintetracético (EDTA) y el otro sin EDTA para la obtención de suero sanguíneo; tanto la sangre como el suero se almacenaron a $-20{ }^{\circ} \mathrm{C}$ hasta su análisis. Las muestras con EDTA se analizaron por PCR y se confirmaron con un SB, mientras que en los sueros correspondientes se utilizó una prueba de IFI desarrollada para este fin (Pereyra 2009).

\section{DETECCIÓN DE M. SUIS MEDIANTE LA REACCIÓN EN CADENA DE LA POLIMERASA}

Extracción y purificación del ADN. Se utilizó un kit comercial de extracción de ADN (Generation ${ }^{\circledR}$ Capture Column Kit, Gentra Systems, Minneapolis, MI, EEUU) basado en un sistema de columnas simples más centrifugación. Se siguieron las especificaciones de uso del fabricante para extraer y purificar el ADN genómico a partir de un volumen de $200 \mu \mathrm{l}$ de sangre entera con EDTA.

Reacción en cadena de la polimerasa. Las reacciones estándares de amplificación se llevaron a cabo en un ciclador térmico tipo Peltier (PTC-100® Peltier Thermal Cycler, MJ Research, Inc, Waltham, MA, EEUU). Los primers utilizados para la amplificación del gen $16 \mathrm{~S}$ del ARN ribosomal fueron reportados previamente (Messick y col 1999); el primer sentido (f2) fue 5' GCT TAA CAA GTG TTC GCG GT 3' y el primer antisentido (r2) estaba conformado por las bases siguientes: 5' CTT AAC TCC AAT CA AAT TAC C 3 . El perfil de ciclado térmico consistió en un paso inicial de desnaturalización a $94{ }^{\circ} \mathrm{C}$ durante 10 minutos seguido de 32 ciclos a $94{ }^{\circ} \mathrm{C}$ por 1 minuto, $54{ }^{\circ} \mathrm{C}$ por 1 minuto, y $72{ }^{\circ} \mathrm{C}$ por 2 minutos, con un paso final de extensión a $72{ }^{\circ} \mathrm{C}$ por 7 minutos. Los productos amplificados fueron analizados por electroforesis en un gel con el $1 \%$ de agarosa y $1 \mu \mathrm{g} / \mathrm{ul}$ de bromuro de etidio. Dichos productos amplificados se centrifugaron brevemente; a cada reacción de $25 \mu \mathrm{l}$, se agregaron $5 \mu \mathrm{l}$ de buffer de carga y el volumen total se agregó en cada pocillo. La electroforesis fue corrida durante una a dos horas a 120$150 \mathrm{~V}$. Los geles fueron fotografiados bajo luz ultravioleta (sistema de imágenes Alpha Imager 2200, Alpha Innotech Corporation, San Leandro, CA, EEUU). En cada corrida se incluyó un control M. suis positivo, un control $M$. suis negativo y un marcador estándar del tamaño molecular del ADN (HI-Lo DNA marker Minnesota Molecular, Minneapolis, MN, EEUU).

Para asegurar la extracción exitosa del ADN y de que su amplificación no estuviera impedida por inhibidores, se llevó a cabo una reacción de PCR para el gen $\beta$-actina (gen de control interno). Los primers utilizados en esta reacción fueron: sentido, 5'-GGGACCTGACCGACTACCTC-3', y antisentido, 5'-TGTTGGCGTAGAGGTCCTTC-3'. El perfil de ciclado comenzó con un paso de desnaturalización inicial de 5 minutos a $94{ }^{\circ} \mathrm{C}$, seguido de 35 ciclos de 30 segundos a $94{ }^{\circ} \mathrm{C}, 30$ segundos a $62{ }^{\circ} \mathrm{C}$, y 1 minuto a $72{ }^{\circ} \mathrm{C}$. Las muestras fueron guardadas a $4{ }^{\circ} \mathrm{C}$ hasta su análisis. Los productos de $437 \mathrm{pb}$ fueron separados por electroforesis.

Todos los resultados de las reacciones de la PCR fueron confirmados con un SB.

Southern Blot. Los geles provenientes de la PCR fueron sometidos a la desnaturalización con álcalis y neutralización estándares, luego se transfirieron los fragmentos de ADN a una membrana (Hybond-N+ RPN303B, Amersham Pharmacia Biotech, Arlington Heighers, IL, EEUU) cargada positivamente que fue incubada por 16 horas. El buffer de transferencia utilizado para este procedimiento fue 10X SSC (1X SSC corresponde a cloruro de sodio $0,15 \mathrm{M}$, citrato de sodio 0,15 M). Un fragmento de 839pb del gen de ARNr 
16S de $M$. suis fue amplificado por PCR usando para su amplificación específica el set de primers previamente descrito pero con el agregado de digoxigenina a uno de ellos. El producto fue purificado usando un kit de extracción (Qiaex II Gel Extraction Kit, Qiagen Inc, Valencia, CA, EEUU) y revelado por el método no radioactivo basado en la unión específica a la digoxigenina unida a uno de los primers (DIG Nucleic Acid Detection Kit, Roche Diagnostics Corporation, Indianopolis, IN, EEUU). Las membranas fueron prehibridizadas durante $\geq 10$ minutos en buffer de hibridización comercial (PerfectHyb ${ }^{\text {TMPlus, }}$ Sigma-Aldrich Corp St Louis, MO, USA). Se llevó a cabo durante 16 horas una hibridización bajo condiciones de estringencia a $68^{\circ} \mathrm{C}$ en el mismo buffer con la adición de aproximadamente $10 \mathrm{ng} / \mathrm{ml}$ de la sonda marcada con digoxigenina. Las membranas fueron lavadas y reveladas de acuerdo al protocolo del fabricante para la detección por quimioluminiscencia y autorradiografía.

\section{DETECCIÓN DE ANTICUERPOS CONTRA $M$. SUIS UTILIZANDO LA PRUEBA DE INMUNOFLUORESCENCIA INDIRECTA}

Infección experimental con $M$. suis y recolección de muestras de los animales inoculados. En esta experiencia se siguieron las recomendaciones legales vigentes sobre el cuidado de animales (SENASA 2002). Se esplenectomizaron cinco cerdos procedentes de granjas sin historia clínica de enfermedad, libres de $M$. suis según la PCR (PCR-) y por exámenes microscópicos repetidos de extendidos teñidos con May Grünwald-Giemsa. Tres semanas después de la esplenectomización, los animales fueron inoculados intramuscularmente con $3 \mathrm{ml}$ de sangre procedente de un cerdo PCR positivo (PCR+) a la infección con $M$. suis con síntomas de la enfermedad. Los cerdos inoculados fueron monitoreados diariamente por examen físico, control de temperatura corporal, y coloraciones hematológicas; a los cinco días de la inoculación también se corroboró la infección a través de PCR.

Obtención del antígeno para la IFI. En el momento en que se detectaba una bacteriemia elevada ( $\geq 80 \%$ de GR infectados) se obtenía sangre de los animales afectados en proporción 1:1 con solución de Alsever (glucosa $111,0 \mathrm{mM}$ + citrato de sodio 27,2 $\mathrm{mM}$ + cloruro de sodio $71,8 \mathrm{mM}, \mathrm{pH} 6,1)$ como anticoagulante. Inmediatamente se centrifugaba a bajas revoluciones (450 $\mathrm{g}$ durante 10 minutos) para preservar la integridad de los eritrocitos y evitar el desprendimiento de $M$. suis de los GR, una primera vez para eliminar el anticoagulante y tres veces más con solución bufferada de fosfatos (PBS: cloruro de sodio $137,0 \mathrm{mM}+$ cloruro de potasio 2,0 $\mathrm{mM}+$ fosfato disódico 13,5 mM + fosfato monopotásico 1,5 mM, $\mathrm{pH} 7,4)$ para lavar los GR de plasma. El sedimento de GR parasitados y lavados se diluyó con PBS estéril (1:12) y se dispensaron $10 \mu \mathrm{l}$ de esta solución en cada pocillo de portaobjetos para serología $(75$ x $25 \mathrm{~mm}$ y 12 pocillos de $6 \mathrm{~mm}$ de diámetro). Los portaobjetos se dejaron secar a temperatura ambiente por una hora, se fijaron durante diez minutos en alcohol metílico y se almacenaron en paquetes de cinco portaobjetos en freezer de $-20{ }^{\circ} \mathrm{C}$.

Metodología adoptada para la realización de la prueba de IFI. Se retiraron los portaobjetos de su almacenamiento $\mathrm{a}-20{ }^{\circ} \mathrm{C}$ y luego que alcanzaron la temperatura del ambiente, se colocó en cada pocillo con el antígeno, $10 \mu \mathrm{l}$ de cada uno de los 282 sueros a analizar diluidos 1:2 en PBS pH 7,2, ya que la máxima concordancia entre las pruebas de IFI y PCR se obtuvo usando el suero diluido 1:2 (datos no mostrados). Seguidamente se incubaron a $37^{\circ} \mathrm{C}$ en cámara húmeda por una hora y se lavaron dos veces con PBS y agua destilada, en agitación durante diez minutos. Se agregaron luego en cada pocillo $10 \mu \mathrm{l}$ de un antisuero anticerdo conjugado con isotianato de fluoresceína diluido 1:64 con PBS (Sigma Anti-pig IgG Whole molecule FITC Conjugate). Se incubaron y lavaron nuevamente como ya fue descripto, se secaron a temperatura ambiente y se colocaron cubreobjetos utilizando como líquido de montaje glicerol bufferado al $90 \%$ pH 8,9. Se realizó la lectura de las reacciones observando con microscopio óptico de fluorescencia (Leitz Dialux 20, 100X, 250X y $1000 X)$. Se consideró la reacción positiva (IFI+) cuando se detectaban cuerpos fluorescentes sobre los glóbulos rojos. Se incluyeron un control positivo (muestras de cerdos inoculados experimentalmente PCR+e IFI+) y un control negativo (muestras de cerdos esplenectomizados que no manifestaron síntomas, PCR- e IFI-) en cada portaobjetos, y un control de antígeno (PBS en reemplazo de suero para corroborar que el conjugado no detectaba IgG no-específicas) cada cinco portaobjetos.

\section{ANÁLISIS ESTADÍSTICO}

El objetivo del análisis estadístico fue estimar las probabilidades de que la PCR y la IFI fueran capaces de identificar los animales infectados como positivos y los animales no infectados como negativos, es decir, la $\mathrm{S}$ y la $\mathrm{E}$ de las pruebas diagnósticas. El verdadero estatus de los animales (infectados y no infectados) se consideró desconocido y como es común en el diagnóstico de enfermedades infecciosas, no se dispone de una prueba con $\mathrm{S}$ y E perfectas para la detección de la infección por $M$. suis. La incertidumbre previa referida a los valores de $\mathrm{S}$ y $\mathrm{E}$ de las pruebas y de la probabilidad de que la enfermedad esté presente en la población muestreada (prevalencia, $\mathrm{p}$ ) fueron modeladas a través de una distribución de probabilidad conocida como distribución a priori. La información recolectada a campo fue utilizada para modificar esa distribución a priori y así producir una nueva distribución referida a la incertidumbre en los valores de los parámetros de interés denominada distribución a posteriori. La distribución a posteriori representa la incertidumbre en los valores de $\mathrm{S}$, 
E y p resultantes de la distribución a priori y de los valores recolectados en el estudio. Este procedimiento constituye el eje metodológico de las estimaciones bayesianas de $\mathrm{S}$ y E. Brevemente, en estadística bayesiana la probabilidad de identificación correcta de un resultado (S, E) se estima en forma condicional a la probabilidad de presencia de la enfermedad en la población muestreada y teniendo en cuenta la incertidumbre previa del investigador con respecto a los valores reales de los parámetros. Por lo tanto, a diferencia de la estadística frecuentista la subjetividad no solamente no es ignorada sino que, en cambio, se la utiliza para cuantificar los parámetros de interés. Los detalles matemáticos de las aplicaciones bayesianas para la estimación de S y E de pruebas diagnósticas pueden consultarse en Suess y col (2002) y Branscum y col $(2004,2005)$.

La incertidumbre a priori de los valores de S, E y p fue modelada usando información reportada previamente en la literatura científica. Los valores a priori más probables de la S (S-PCR) y de la E para esta prueba (E-PCR) fueron asumidos como de 0,99 y de 0,96 , con una credibilidad (IC) del $95 \%$ de que la S-PCR y la E-PCR fueran, respectivamente, mayores del 0,95 y 0,9 (Messick y col 1999, Hoelzle y col 2003 y 2007).

No existían estimaciones previas para los valores de la S (S-IFI) y la E de la IFI (E-IFI) para el diagnóstico de $M$. suis, pero se esperaba que esta prueba sea menos sensible y específica que la PCR. Utilizando estimaciones de la habilidad diagnóstica de la IFI para la infección por Bartonella spp en cerdos (Maurin y col 2002, Vermeulen y col 2007) y para Eperythrozoon ovis en ovejas (Nicholls y col 1986), se asumió una $S$ y E más probables para esta prueba de S-IFI $=0,7($ IC95\% $>0,5)$ y de E-IFI $=0,9$ (IC95\% > 0,8).

Con respecto a la prevalencia de $M$. suis, la información que arrojaban los estudios en cerdos de países como Estados Unidos, Brasil y Suiza (Smith y Tamra 1975, Hoelzle y col 2003, Guimaraes y col 2007, Hoelzle y col 2007) sugería que en las regiones en donde la enfermedad estaba presente, la infección alcanzaba una $\mathrm{p}=0,2$ con una credibilidad del $95 \%$ de que sea menor del $40 \%$. Utilizando estos valores, las distribuciones a priori fueron definidas utilizando el software BetaBuster ${ }^{1}$, como distribuciones beta con parámetros de 88.280 y 1.882 (S-PCR), 71.056 y 3.919 (E-PCR), 13.322 у 6.281 (S-IFI), 42.573 y 5.619 (E-IFI), y 4.461 y 14.844 (p).

No se sabe si los cerdos PCR+ tienen mayor probabilidad de ser IFI+ que los cerdos PCR-, o si los resultados IFI- tienen mayores chances de ser cerdos PCR- que los IFI+, y por tal motivo y de manera conservadora se asumió que los resultados de las pruebas eran condicionalmente dependientes entre sí. La sensibilidad del modelo a la definición de las distribuciones a priori fue evaluada asumiendo alternativamente distribuciones a priori uniformes $(0,1)$ para los valores de S-PCR, E-PCR, S-IFI, E-IFI y p (figura 1).

1 www.epi.ucdavis.edu/diagnostictests

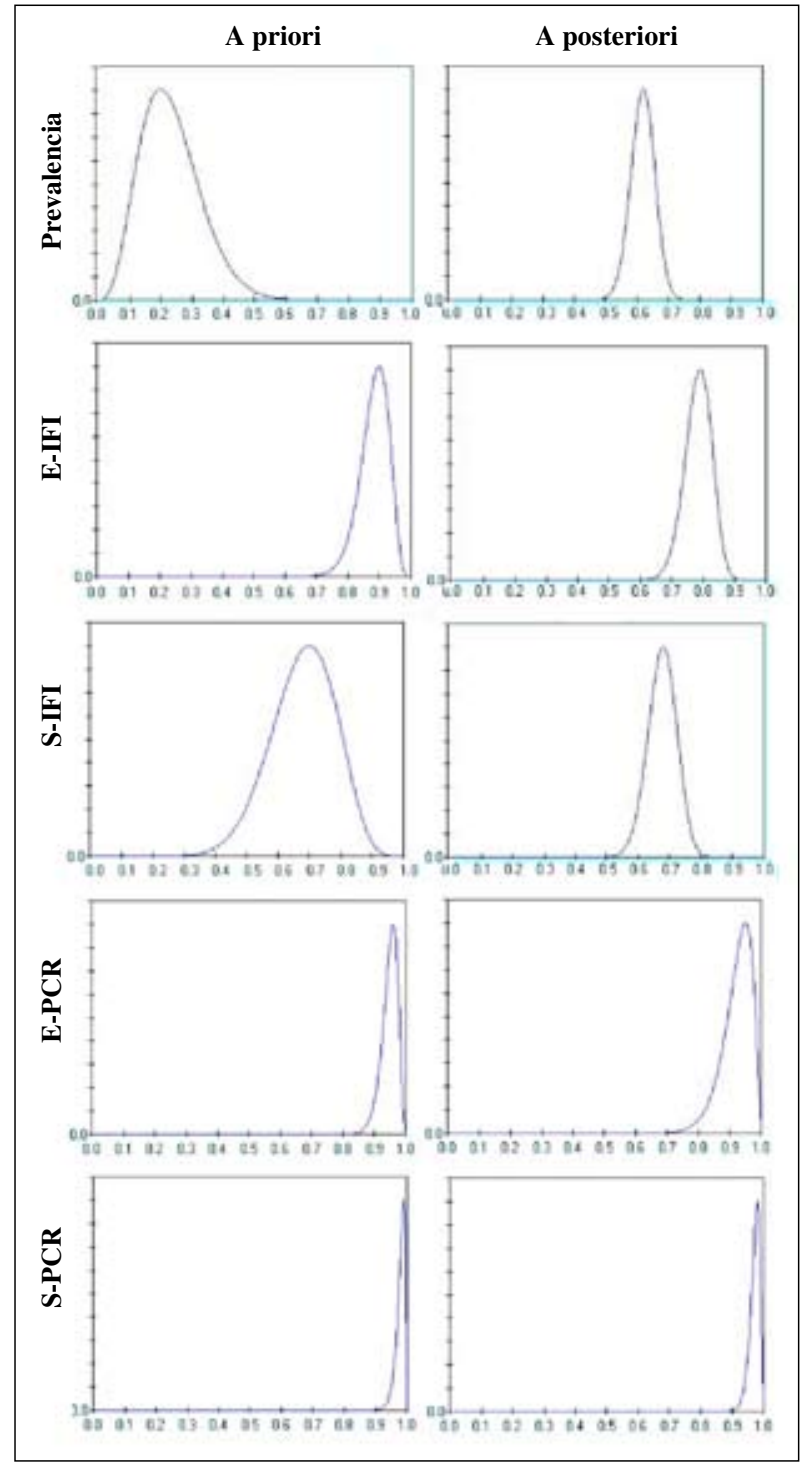

Figura 1. Sensibilidad del modelo a la definición de las distribuciones a priori para la sensibilidad (S) y especificidad (E) de la reacción en cadena de la polimerasa (PCR) y de la prueba de inmunofluorescencia indirecta (IFI), y para el porcentaje de resultados positivos en la población muestreada (prevalencia).

Sensitivity of the model to the definition of prior distributions for the polymerase chain reaction (PCR) and indirect immunofluorescens assay (IFI) sensitivity (S) and specificity (E), along with the percentage of positive results in the studied population (prevalence).

El modelo fue corrido con tres diferentes grupos de 20 animales seleccionados al azar para testear la sensibilidad de los resultados en un grupo particular de individuos. La superposición de intervalos de probabilidad y cambios $<5 \%$ en la distribución posterior fueron interpretados como indicadores de la robustez del modelo. Todos los cálculos se realizaron utilizando el software WinBUGS (Spiegelhalter y col 1996) y los resultados fueron computados mediante 20.000 interacciones del modelo después que fueron descartadas las 1.000 iniciales. La estabilidad, 
convergencia y ausencia de correlación de las estimaciones se evaluaron utilizando procedimientos estándares.

\section{RESULTADOS}

Ciento veinticuatro $(44,0 \%)$ muestras fueron positivas tanto para la PCR como para la IFI, mientras que $71(25,2 \%)$ resultaron negativas para ambas pruebas. Sesenta y una $(21,6 \%)$ muestras fueron PCR+ pero IFI-; contrariamente, $26(9,2 \%)$ muestras fueron IFI+ y PCR-.

Se calcularon las distribuciones de probabilidad posteriores estimadas de $\mathrm{S}-\mathrm{PCR}=0,982$ (IC95\% = 0,942-0,997), $\mathrm{E}-\mathrm{PCR}=0,946(\mathrm{IC} 95 \%=0,873-0,984), \mathrm{S}-\mathrm{IFI}=0,682$ $(\mathrm{IC} 95 \%=0,615-0,753), \mathrm{E}-\mathrm{IFI}=0,787(\mathrm{IC} 95 \%=0,712-$ $0,863)$ у $\mathrm{p}=0,622(\mathrm{IC} 95 \%=0,554-0,684)($ figura 1$) . \mathrm{La}$ correlación estimada $(\mathrm{R})$ entre los resultados de las pruebas fue $\mathrm{R}=0,010$ (IC95\% $=-0,118-0,195)$ para los animales infectados y $\mathrm{R}=0,049$ (IC95\% $=-0,133-0,407$ ) para los cerdos no infectados. Los cambios en la forma de la distribución a priori por una distribución no informativa uniforme (0, 1 alternativamente para cada parámetro) o la aplicación de la prueba a subgrupos de 20 sueros seleccionados al azar no resultaron en estimaciones significativamente diferentes de los valores de los parámetros de interés. En el caso de la E de PCR, el asumir una distribución $a$ priori no informativa resultó en estimaciones a posteriori vagas, sugiriendo que el resultado es dependiente de los valores de incertidumbre a priori seleccionados por el investigador. Las estimaciones fueron estables y carentes de autocorrelación (figura 2).

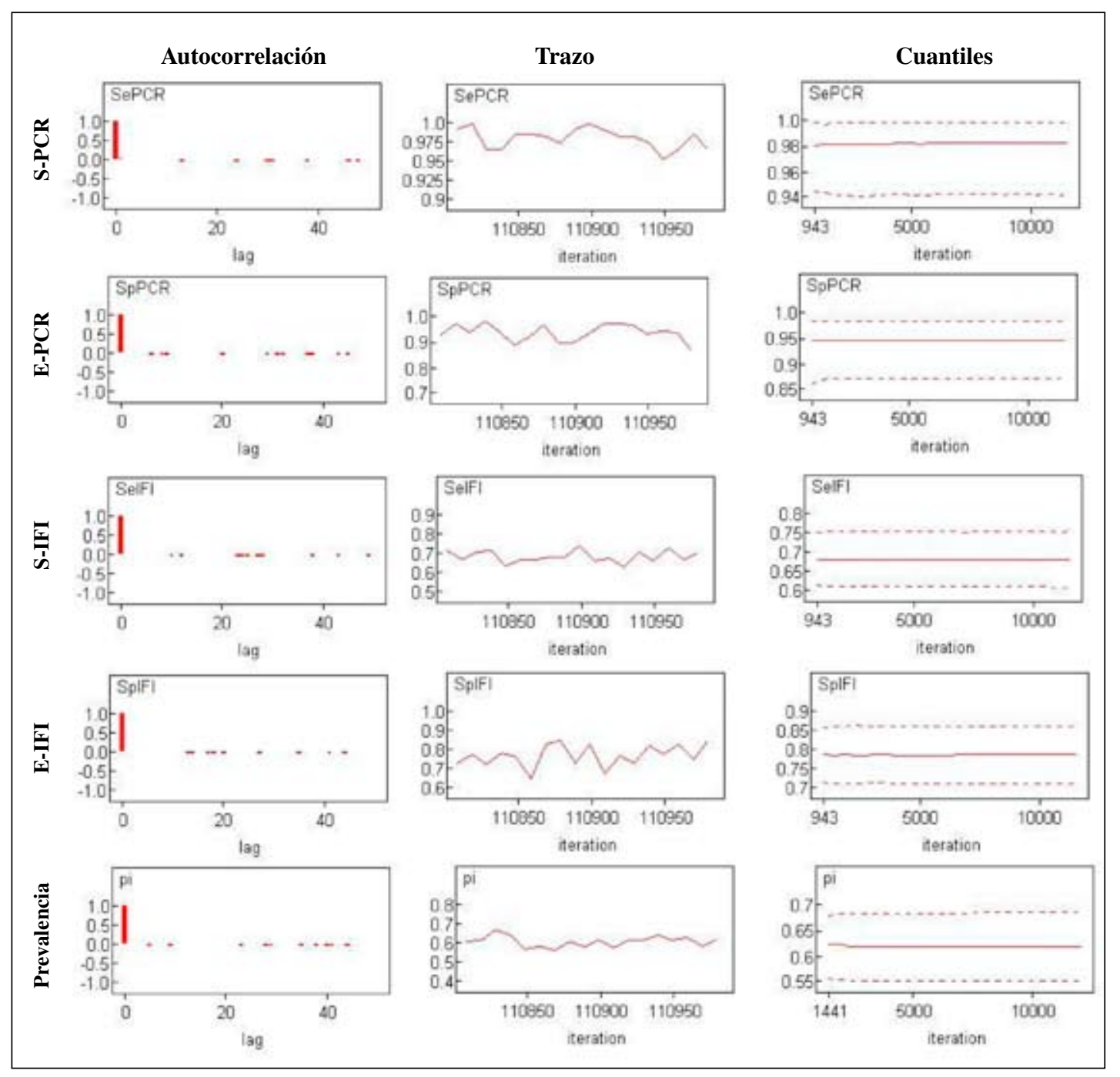

Figura 2. Autocorrelación, convergencia y estabilidad de las predicciones para la sensibilidad (S) y la especificidad (E) de la reacción en cadena de la polimerasa (PCR) y la prueba de inmunofluorescencia indirecta (IFI), y para el porcentaje de resultados positivos en la población muestreada (prevalencia). Las salidas de los gráficos corresponden al programa WinBUGS.

Autocorelation, convergence, and stability of predictions of the sensitivity (S) and specificity (E) of the polymerase chain reaction (PCR) and indirect immunofluorescens assay (IFI) tests, along with the percentage of positive results in the studied population (prevalence). The figures display the outcomes produced by the WinBugs software. 


\section{DISCUSIÓN}

El estudio realizado pudo confirmar por un lado la presencia de $M$. suis en las muestras analizadas y además estimar la $\mathrm{S}$ y la $\mathrm{E}$ de estas dos pruebas diagnósticas para la detección de $M$. suis en una población de cerdos. Como se esperaba, se comprobó que el ensayo de PCR poseía una $\mathrm{S}(\mathrm{S}-\mathrm{PCR}=0,982$; IC95\% $=0,942-0,997)$ y $\mathrm{E}(\mathrm{E}-\mathrm{PCR}=0,946$; IC95\% $=0,873-0,984)$ elevadas para el diagnóstico de esta infección. Existen escasos estudios a nivel mundial en donde la PCR haya sido utilizada para definir la presencia de $M$. suis en una población de cerdos; la S y la E de la PCR nunca habían sido evaluadas en el campo en un número tan elevado de muestras. Notoriamente, la estimación de E de la PCR, a diferencia de los otros parámetros estimados, fue sensible a los valores de incertidumbre a priori utilizados en el trabajo (figura 1). De esta manera, si las estimaciones a priori asumidas para la E del PCR fueran erróneas, entonces los resultados obtenidos en este trabajo quizás también sean inexactos. Sin embargo, los autores consideran que de acuerdo al estado del conocimiento actual, asumir que la E de la PCR es, con un 95\% de confianza, superior al 90\% es prudente y adecuado, ya que, típicamente, la PCR es una técnica diagnóstica de alta especificidad. Los valores a posteriori de los otros parámetros (p en la muestra, $\mathrm{S}$ de la PCR y la IFI y E de la IFI) no fueron influenciados por el uso de distribuciones no informativas (cuadro 1). Por lo tanto consideramos que las estimaciones presentadas en este trabajo son robustas, dado el estado actual del conocimiento sobre el tema.

La prueba de IFI, más sencilla, accesible, y adecuada para el análisis masivo que la PCR, fue como era previsible sustancialmente menos segura si se la compara con la PCR (S-IFI $=0,682$, IC95\% $=0,615-0,753 ;$ E-IFI $=0,787$, IC95\% $=0,712-0,863)$. Sin embargo la S estimada aquí hace que su uso pueda ser adecuado como prueba tamiz dirigida a la identificación de granjas infectadas.

La baja correlación entre los resultados de PCR y de IFI para los animales infectados $(\mathrm{R}=0,01)$ y para los noinfectados $(R=0,05)$ es seguramente la consecuencia de los diferentes principios biológicos que sostienen ambas pruebas. Mientras que la PCR es una técnica destinada a la estimación de la infección por $M$. suis a través de la amplificación de segmentos del ADN del agente, la prueba de IFI se basa en la detección de anticuerpos producidos por los cerdos en respuesta al agente. Es así que es muy posible que muchos de los cerdos que fueron positivos a PCR pero negativos a IFI hayan sido recientemente infectados por M. suis y por ende el tiempo haya sido demasiado escaso para el desarrollo de anticuerpos contra la enfermedad o que los niveles de IgG sean pobremente detectados por la IFI luego de un tiempo de infección. Se observó en el laboratorio que luego de 16 semanas, los títulos eran casi indetectables por esta prueba en los cerdos inoculados experimentalmente (Pereyra 2009).
Hasta ahora se pensaba que los animales no podían liberarse de la infección por $M$. suis una vez invadidos por la bacteria (Heinritzi 2000, Mesick 2004, Neimark ycol 2001). Sin embargo, si al tiempo de la evaluación del estatus sanitario el huésped se hubiera liberado recientemente de M. suis, el animal sería PCR-e IFI+. Se ha observado que los cerdos esplenectomizados, inoculados y enfermos que habían sido tratados por un período prolongado con oxitetraciclina no eran capaces de transmitir la infección luego de inocular una muestra de su sangre a otro cerdo esplenectomizado (Pereyra 2009) como se esperaría que lo hiciera un portador asintomático (Heinritzi 2000). Si bien nunca se había mencionado el hecho de que un cerdo infectado por M. suis no permanezca en estado de portador, existen datos que apoyan esta hipótesis, ya que gatos infectados por hemoplasmas se transformaron en PCR- luego de un año de tratamiento (Willi y col 2007). Los resultados PCR- e IFI+ también se explicarían si los cerdos recién nacidos recibieran anticuerpos contra $M$. suis desde la madre. En este caso la IFI debería ser capaz de detectar la presencia de anticuerpos pero la PCR no detectaría el agente; varios de los casos en donde la IFI fue positiva y la PCR fue negativa, se correspondieron con muestras provenientes de lechones. Sería esperable que las cerdas infectadas transmitan anticuerpos a sus camadas, aunque todavía no se han realizado estudios sobre inmunidad pasiva para esta enfermedad.

Las estimaciones posteriores acerca de la proporción de cerdos infectados con M. suis $(\mathrm{P}=0,622$; IC95\% $=0,554-$ $0,684)$ fueron sustancialmente más elevadas que las expectativas a priori de encontrar $<0,4$ cerdos infectados en la población muestreada. Estas evidencias son considerablemente superiores que los hallazgos serológicos reportados previamente. Los estudios realizados en Estados Unidos utilizando IHA sobre un gran número de muestras de cerdos (>10.000) (Smith y Tamra 1975) mostraron que aproximadamente el $20 \%$ de los animales eran seropositivos con títulos $\geq 40$. Probablemente en animales de campo los títulos declinen más rápidamente (Heinritzi 2000) y la prueba no pueda detectar cerdos infectados crónicamente; se comprobó en numerosas oportunidades que la IHA arrojaba muchos falsos negativos (Baljer 1985, Heinritzi 2000, Mesick 2004). Al contrario, en cerdos inoculados experimentalmente, los niveles de anticuerpos se mantienen elevados debido a que se producen reactivaciones continuas a consecuencia de la esplenectomización (Heinritzi 2000, Pereyra 2009). Si bien los escasos estudios anteriores en los cuales se había utilizado PCR arrojaban niveles de positividad menores al 33\% (Hoelze y col 2003, Guimaraes 2007), un relevamiento reciente realizado en China determinó que el $85 \%$ de los animales analizados estaban infectados con M. suis (Luan y col 2009). Muy probablemente, los resultados dispares estén relacionados con las diferentes formas de muestreo utilizadas que parecieran restringirse en general a categorías productivas o áreas geográficas determinadas. 
Este estudio con técnicas moleculares es el primero en realizarse en Argentina confirmando así la presencia de la infección por M. suis en el país, y proveyendo estimaciones sobre la $\mathrm{S}$ y la $\mathrm{E}$ de las dos pruebas diagnósticas. Los resultados de este análisis pueden ser útiles para diseñar e implementar otros estudios dirigidos al mejor entendimiento de las características epidemiológicas de la enfermedad y su impacto potencial sobre la industria de cerdos en las regiones infectadas. A pesar que estos resultados no pueden generalizarse a otras poblaciones no incluidas en la investigación, sí provee de estimaciones generales sobre la seguridad esperable en la aplicación de estas pruebas diagnósticas en otras poblaciones o regiones.

Los resultados indican que la prueba de PCR es una técnica certera para el diagnóstico de la infección por $M$. suis en cerdos por lo que será fundamental para futuros estudios tendientes a comprender la patogenia de la enfermedad y la transmisión de M. suis (Messick 2004), o comprobar la exacerbación de otras infecciones presentes en los cerdos (Pereyra y col 2006). Ya que los porcinos son donadores potenciales de órganos al hombre, también se podrá aplicar para dilucidar si es posible la transmisión de este agente a los humanos (Puntaric y col 1990, Dos Santos y col 2008, Luang 2009).

Finalmente, la aplicación del modelo bayesiano puede extenderse a la evaluación y caracterización de pruebas diagnósticas aplicadas a otras enfermedades infecciosas de interés veterinario.

\section{RESUMEN}

Para comprender el impacto de la infección por Mycoplasma suis en la producción de cerdos, así como la dinámica epidemiológica en las regiones infectadas, se necesita desarrollar métodos diagnósticos capaces de diferenciar los individuos infectados de los no infectados. Los objetivos del estudio fueron confirmar la presencia de la infección por M. suis en la Argentina y estimar la sensibilidad (S) y la especificidad (E) de las pruebas de inmunofluorescencia indirecta (IFI) y de la reacción en cadena de la polimerasa (PCR) para la detección del agente. Se recolectó sangre de 282 cerdos pertenecientes a 38 granjas. La S y la E de los tests fueron estimadas utilizando un modelo Bayesiano para resultados condicionalmente dependientes y en ausencia de una prueba de oro. Se estimó que la $\mathrm{PCR}$ era un método con una $\mathrm{S}$ y $\mathrm{E}$ elevadas $(\mathrm{S}=0,982$, IC95\% $=0,942-0,997 ; \mathrm{E}=0,946$, IC95\% = 0,873-0,984). Para la prueba de IFI se estimaron una $\mathrm{S}$ y $\mathrm{E}$ significativamente $(\mathrm{P}<0.05)$ menores $(\mathrm{S}=0,682, \mathrm{IC} 95 \%=0,615-0,753 ; \mathrm{E}=0,787, \mathrm{IC} 95 \%=0,712-0,863)$. La correlación entre los resultados de las pruebas fue bajo tanto para los animales infectados $(R=0,010$, CI95\% $=-0,118-0,195)$ como para los no infectados $(\mathrm{R}=0,049, \mathrm{CI} 95 \%=-0,133-0,407)$. La probabilidad a posteriori de encontrar un animal infectado en una población con una prevalencia similar a la de los animales muestreados fue de 0,622 (IC95\% = 0,554-0,684). El estudio pudo confirmar la presencia de M. suis en Argentina y la habilidad diagnóstica de la PCR para la detección de la bacteria.

\section{AGRADECIMIENTOS}

A Therese Eggett de la Universidad de Illinois, Estados Unidos por su meticulosa asistencia a este proyecto.

\section{REFERENCIAS}

Anziani O, C Ford, H Tarabla. 1986. Eperythrozoonosis porcina en la República Argentina. Rev Med Vet 67, 99-101.

Ayroud M, S Leavitt, G Higgs. 1994. Eperythrozoonosis in swine. Can Vet J 35,54-55.

Baljer G, K Heinritzi, L Wieler. 1989. Indirect hemagglutination for Eperythrozoon suis detection in experimentally and spontaneously infected swine. J Vet Med B 36,417-423.

Branscum A, I Gardner, W Johnson. 2004. Bayesian modeling of animal and herd level prevalences. Prev Vet Med 66,101-112.

Branscum A, I Gardner, W Johnson. 2005. Estimation of diagnostic test sensibility and specificity through Bayesian modeling. Prev Vet Med 68,145-163.

Brownback A. 1981. Eperythrozoonosis as a cause of infertility in swine. Vet Med Small Anim Clin 76, 375-378.

Cane F, N Pereyra, M Pereyra. 1994. Observaciones sobre la infección natural por Eperythrozoon suis. II Congreso Nacional de Producción Porcina, Rosario, Argentina.

Dos Santos A, R dos Santos, A Biondo, J Dora, L Goldani, S de Oliveira, A de Sá Guimaraes, J Timenetsky, H de Morais, F González, J Messick. 2008. Hemoplasma infection in HIV-positive patient, Brazil. Emerg Infect Dis 14, 1922-1924.

Guimaraes A, A Biondo, A Lara, J Messick. 2007. Exploratory study of Mycoplasma suis (Eperythrozoon suis) on four commercial pig farms in southern Brazil. Vet Rec 160, 50-53.

Gwaltney S, M Hays, R Oberst. 1993. Detection of Eperythrozoon suis using the polymerase chain reaction. $J$ Vet Diag Invest 5, 40-46.

Heinritzi K. 2000. Eperitrozoonosis. En: Straw B, D'Allaire S, Mengeling W, Taylor D (eds), Enfermedades del Cerdo. $8^{\mathrm{a}}$ ed. Intermédica, Buenos Aires, Argentina, Pp 363-367.

Henry S. 1979. Clinical observations on Eperythrozoonosis. J Am Vet Med Assoc 174, 601-603.

Hoelzle L, D Adelt, K Hoelze, K Heinritzi, M Wittenbrink. 2003. Development of a diagnostic PCR assay based on novel DNA sequences for the detection of Mycoplasma suis (Eperythrozoon suis) in porcine blood. Vet Microbiol 93, 185-196.

Hoelzle LE. 2007. Significance of haemotrophic mycoplasmas in veterinary medicine with particular regard to the Mycoplasma suis infection in swine. Berl Munch Tierarztl Wochenschr 120, 34-41.

Kloster A, C Descarga, P Davies, H Piscitelli, L Díaz, G Zielinski. 1985. Eperitrozoonosis porcina: observaciones sobre la infección natural y experimental. V Congreso Argentino de Ciencias Veterinarias, La Plata, Argentina, resumen 171.

Luang C, A Liang, C Yao, Z Yang, J Zhu, L Cui, F Yu, N Zhu, X Yang, $\mathrm{X}$ Hua. 2009. Prevalence of Mycoplasma suis (Eperythrozoon suis) infection in swine and swine-farm workers in Shangai, China. Am J Vet Res 70, 890-894.

Maurin M, J Rolain, D Raoult. 2002. Comparison of in-house and commercial slides for detection by immunofluorescence of IgG and $\mathrm{M}$ against Bartonella henselae and Bartonella quintana. Clin Diagn Lab Immunol 9, 1004-1009.

Messick J, S Cooper, M Huntley. 1999. Development and evaluation of a polymerase chain reaction assay using the 16S rRNA gene for detection of Eperythrozoon suis infection. J Vet Diagn Invest $11,229-236$.

Messick J. 2004. Hemotrophic mycoplasmas (hemoplasmas): a review and new insights into pathogenic potencial. Vet Clin Pathol 33, 2-13.

Neimark H, K Johansson, Y Rikihisa, J Tully. 2001. Proposal to transfer some members of the genera Haemobartonella and Eperythrozoon to the genus Mycoplasma with descriptions of "Candidatus Mycoplasma haemofelis", "Candidatus Mycoplasma haemomuris", "Candidatus Mycoplasma haemosuis" y "Candidatus Mycoplasma wenyonni". Int J Syst Evol Microbiol 51, 891-899. 
Neimark H, K Johansson, Y Rikihisa, J Tully. 2002. Revision of haemotrophic Mycoplasma species names. Int J Syst Evol Microbiol 52,683 .

Nicholls T, P Veale. 1986. A modified indirect immunofluorescent assay for the detection of antibody to Eperythrozoon ovis in sheep. Aust Vet $J 63,157-159$.

Pereyra N, J Sarradell, F Cane, S Francois, C Pidone, E Comba, F Rodríguez, A Guglielmone. 2006. Detección de Mycoplasma suis en Casos Clínicos con el Síndrome del Desmedro Multisistémico Postdestete en Porcinos. Rev Arg Microbiol 38, 130-133.

Pereyra NB. 2009. Aspectos clínicos, epidemiológicos y terapéuticos de la hemoplasmosis (eperitrozoonosis) porcina. Tesis Doctoral, Facultad de Ciencias Veterinarias, Universidad de Buenos Aires, Argentina.

Puntaric V, D Borcic, D Vukelic, T Jeren, V Brek, T Wikerhauser, B Richter. 1990. Eperythrozoonosis-a new diseases in human pathology. Giorn Malat Inf Parassit 42, 539-540.

Rikihisa Y, M Kawahara, B Wen, G Kociba, P Fuerst, F Kawamori, C Suto, S Shibata, m Futohashi. 1997. Western immunoblot analysis of Haemobartonella muris and comparison of 16S rRNA gene sequences of $H$. muris, $H$. felis, and Eperythrozoon suis. J Clin Microbiol 35, 823-9.

SENASA, Servicio Nacional de Calidad Agroalimentaria, Argentina, 2002. Resolución 617/02.
Smith A, R Tamra. 1975. An Indirect Hemagglutination Test for the Diagnosis of Eperythrozoon suis Infection in Swine. Am J Vet Res $36,1319-1321$.

Spiegelhalter D, A Thomas, N Best, W Gilks. 1996. BUGS: Bayesian inference using Gibbs Sampling, Version 0.50. MRC. Biostatitics Unit, Cambridge, UK.

Splitter E. 1950. Eperythrozoon suis, the etiologic agent of ictero-anemia or an anaplasmosis-like disease in swine. Am J Vet Res 11, 324-330.

Splitter EJ, E Castro. 1957. Antibiotic therapy in acute Eperythrozoonosis of swine. J Am Vet Med Assoc 131, 293-294.

Suess E, I Gardner, W Jhonson. 2002. Hierarchical Bayesian model for prevalence inferences and determination of a country's status for an animal pathogen. Prev Med Vet 55, 155-171.

Vermeulen M, M Herremans, H Verbakel, A Bergmans, J Roord, P van Dijken, M Peeters. 2007. Serological testing for Bartonella henselae infections in The Netherlands: clinical evaluation of immunofluorescence assay and ELISA. Clin Microbiol Infect 13, 627-634.

Willi B, FS Boretti, S Tasker, ML Meli, N Wengi, CE Reush, H Lutz, R Hofmann Lehmann. 2007. From Haemobartonella to hemoplasma: molecular methods provide new insights. Vet Microbiol 125, 197-209.

Zinn G, G Jese, A Dobson. 1983. Effect of eperythrozoonosis on sow productivity. J Am Vet Med Assoc 182, 369-371. 